\title{
Lírica en la clase de Literatura: una práctica de análisis con un poema de Helena Kolody ${ }^{1}$
}

\author{
Poetry in Literature classes: a practice of analysis with a piece of work by Helena \\ Kolody
}

Resumen: La enseñanza de lírica en las clases de literatura demanda del docente la capacidad de abordaje del poema desde diferentes ángulos que promuevan su estudio. El poema como producto literario ofrece a los profesores la oportunidad de trabajar desde la estructura composicional, las imágenes transmitidas o el mensaje que sea propuesto en éste, en convergencia con otras ramas del conocimiento, como la historia o las artes en general. Para este trabajo presentamos algunas consideraciones didácticas para la enseñanza de lírica, basadas en un poema de la poeta paranaense Helena Kolody. Para ello, nos fundamentamos en los presupuestos teóricos en el área de la recepción como los planteados por Wofgang Iser (1989) y Hans Robert Jauss (1989), los aportes latinoamericanos al estudio de la lírica, de teóricos como Idea Vilariño (2016) y Antonio Candido (2000), entre otros.

Palabras clave: Helena Kolody. Enseñanza de Literatura. Poesía latinoamericana.

Abstract: The teaching of Poetry in Literature classes demands from the teacher the capacity to appproach the poem from diferent points the studies in the area make possible. The poema as a result of a literary product offers the teachers the oportunity to work concerning its compositional estructure, the transmited images in it and the intended message it contains, all this linked with other knoledge matters such as History, or Arts in general. Along this text we present some didactic considerations concerning the teaching of poetry having has an example a poem written by the poet Helena Kolody from the Brazilian State of Paraná. This practice is done under the theoretical support of the aesthetics of reception, by Iser (1989) and Jauss (1989), the Latin American contributions to the studies of poetry, by Idea Vilariño (2016) and Antonio Candido (2000), among others.

Keywords: Helena Kolody. Literature teaching. Latin American poetry.

\section{Introducción}

El proceso de enseñanza/aprendizaje de Literatura ofrece a los involucrados la posibilidad de una experiencia que puede basarse en la realización de trabajos conjugados entre el arte literario con otras ramas del saber. Este hecho, a pesar de parecer una situación de conocimiento general, no deja de otorgar una renovación importante para el contenido literario que, con la figura y función del lector, dan nuevas

${ }^{1}$ Las ideas expresadas en este texto forman parte de la tesis Idea Vilarino y Helena Kolody: cantos a la vida encuentros poéticos en América Latina, con la tutela de la Profa. Dra. Carmen Luna Sellés, en el Programa de Posgrado en Estudios Literarios de la Universidade de Vigo, Vigo/España.

* Máster en Teatro y Artes Escénicas por la Universidade de Vigo, Vigo/España. Doctorando del Programa en Estudios Literarios en la Universidade de Vigo, Vigo/España. E-mail: cj_lopez2@hotmail.com. 
perspectivas que amplían y enriquecen a la obra. La mencionada renovación aparece cuando, al momento de analizar el texto artístico, conseguimos conectar y elaborar posibles visiones que complementan por la acción lectora aquello que fue propuesto por el autor en la obra.

El texto literario en diálogo con otras áreas, y como fue comentado antes con la mirada coautoral del lector, consigue abrir un abanico de posibilidades para el docente y los discentes al momento de realizar reflexiones y estudios sobre el mismo. Así, por ejemplo, la historia, la música, la pintura, la política etc. permiten abordar el texto desde ángulos diferentes que expanden el horizonte propuesto en la obra. Este hecho demanda al profesor y al alumnado la capacidad de apertura a lecturas amplias que contribuyan al enriquecimiento de la Literatura como un objeto cultural que no sólo se limita al texto en sí, sino que, mediante las numerosas interrelaciones sociales, económicas, históricas, artísticas, ofrece al lector un nuevo y más completo carácter de lo que la obra literaria puede representar.

Ahora bien, en el espacio de la sala de clase, la Literatura, que ya ocupa en el día a día un lugar reducido, presenta una cuestión que exige del docente el estudio cuidadoso no sólo del contenido, sino, también, del abordaje al texto. Así, mientras tenemos una gran variedad de contenido de cada uno de los tres grandes géneros literarios, cabe al profesor la selección cuidadosa del modo en que presentará cada uno de estos géneros sin causar en el alumnado una imagen negativa que pueda servir como disculpa para la no lectura en el futuro. Es claro que sería exagerado solicitar el dominio de cada uno de los tres géneros con sus respectivas especificidades al docente. Sin embargo, el conocimiento básico, no por ello simple, de cada uno de los tres grandes géneros con la ayuda de la interdisciplinaridad son, a nuestro parecer, puntos a favor en el acto de enseñar y, además, elementos que el profesor tiene a su alcance para enriquecer la tarea docente.

En lo que respecta a la enseñanza de lírica en la clase de Literatura nos deparamos con una otra cuestión a ser evaluada en el momento de planear el modo de abordaje del contenido. Esa cuestión es: ¿cuál es la manera en que será presentada la obra lírica en la clase? A pesar de que parezca una pregunta obvia, la misma es en realidad una de las primeras cuestiones que deben ser pensadas cuidadosamente y que a veces genera inseguridad en el docente. Pues, dependiendo de la manera cómo será presentado el poema podríamos contribuir a una imagen estereotipada que supone a éste como un texto cuya disposición en verso y utilización del recurso de la rima completa su esencia sin que el lector pueda esperarse alguna otra contribución provechosa del mismo. En este sentido, el del abordaje, el poema, como objeto sonoro por naturaleza, de acuerdo con la poeta y teórica uruguaya Idea Vilariño (2016), presenta numerosos "flancos" de ataque para su estudio y conocimiento. Esos flancos van desde su estructura en ritmo y masa sonora del poema hasta el mensaje que el autor persigue y expresa en el cuerpo del texto escrito.

Para este trabajo será utilizado como ejemplo de un posible análisis un poema de la autora paranaense Helena Kolody. La poeta posee una obra en la que explora diferentes temáticas como la añoranza, el paso del tiempo, la crítica social, la 
musicalidad, entre otros. La temática de crítica social llevó a esta escritora a expresar su preocupación en relación a la niñez en Brasil en la que presenta su visión sobre estos sujetos, que a su parecer, son los más perjudicados de la sociedad. Lo referente a la musicalidad es una constante en sus poemas, característica en la que se apoya la escritora para la construcción lírica. De ese modo, crítica social y musicalidad son los aspectos que dirigen este artículo por ser, desde nuestra perspectiva, temáticas de relevancia en la obra de la poeta y que permiten el trabajo con el poema desde diferentes abordajes. Otro punto que cabe destacar en el presente estudio es la importancia en el conocimiento de autoras latinoamericanas que, así como Helena Kolody, quien mediante el uso delicado de la lengua portuguesa y demostrando el pensamiento de una mujer comprometida con las cuestiones sociales de su país, todavía no consigue la visibilidad merecida sumándose a la numerosa fila de escritoras del continente cuya obra aún hoy sigue bajo una aparente invisibilidad. Aparente porque, no obstante, la obra de la gran poeta de Paraná no figura en la historia literaria brasileña ha ganado numerosos estudios de su obra a nivel académico con investigaciones de Grado y Pos grado.

Esperamos que este breve estudio contribuya para el conocimiento de la obra de esta poeta latinoamericana y de algunos posibles abordajes de la obra lírica en la sala de clase.

\section{LA CRÍTICA SOCIAL EN EL POEMA Y LA MUSICALIDAD EN LAS CONSTRUCCIONES LÍRICAS KOLODYANAS}

El trabajo con el poema nos permite pensar en el texto artístico como la manipulación y dominio concretos del sistema lingüístico en un alto nivel. Estamos frente a una construcción literaria basada en la condensación de ideas en un espacio mínimo, en comparación al género de la novela por ejemplo. En el poema el artista explota el potencial representativo de los signos pero en un texto que se caracteriza, generalmente, como una construcción mucho menor en términos de extensión. Así, el lenguaje artístico del poema se presenta como una contribución en la clase de Literatura que además de expresar aspectos subjetivos del ser es una demostración clara de las posibilidades de comunicación que la lengua nos permite. Para la selección de poemas el docente debería escoger desde qué ángulo será posible presentarlos. La obra poética tiene la capacidad de ser un vehículo transmisor de imágenes y sensaciones en las que el lector participa activamente. Además de la subjetividad que se explora en el texto lírico existen obras que permiten determinados abordajes de análisis que no necesariamente pueden ser aplicados en todos los poemas. En ese sentido no nos referimos únicamente a una cuestión de tema o de forma en el poema, sino que cada texto lírico expresa una variedad considerable de particularidades que nos dejan ver que cada obra artística tiene en sí una construcción diferenciada.

En el continente americano existen otras cuestiones de relevancia que debemos considerar para la selección de obras destinadas a la clase de Literatura como, por ejemplo, el tema. En este sentido, observamos que durante numerosas décadas las mujeres del continente tuvieron un espacio limitado para trasmitir sus ideas y, por lo 
tanto, existieron determinadas temáticas que no podían ser exploradas por las escritoras. El docente de Literatura conseguirá con este tipo de observación en la sala de clase realizar conexiones entre la obra literaria propuesta con la situación histórica del país al que pertenezca la escritora. Esa conexión entre texto y contexto social no se basa en la mención simplificada de los acontecimientos históricos del lugar, sino que se puede expandir para la reflexión del tipo de sociedad al que la autora pertenecía. Así, es posible entender las cuestiones socioeconómicas y culturales que se entrelazan con la figura del escritor en la creación de una obra. Al respecto, la estudiosa Lucía Guerra (2008) expone que

[...] hasta la década de 1970 existió en la cultura de Occidente un prejuicio oculto acerca de la literatura escrita por mujeres. Aparte de las dificultades para publicar, hecho que forzó a algunas escritoras del siglo XIX a utilizar seudónimo masculino, la crítica generalmente no les prestaba mayor atención. Y en caso de que lo hiciera, explicaba y daba un juicio valorativo del texto a partir de una noción estereotípica de lo femenino, destacando aspectos tales como un estilo sutil y poético, la presentación de conflictos del corazón y el esbozo de los trazos íntimos del alma femenina. (GUERRA, 2008, p. 9).

Las escritoras latinoamericanas tuvieron que "amoldarse" a las exigencias del canon existente, de carácter masculino, para que sus obras pudiesen ser publicadas, contemplando en su creación lírica lo que era la visión de lo femenino conforme explica Lucía Guerra. En este sentido, la temática de crítica social genera una faceta en la Literatura escrita por mujeres que contribuye a la lírica sudamericana. Encontramos en obras de esta característica la necesidad de expresión de aspectos relacionados con insatisfacciones con el contexto social que rodea a las escritoras. Esa posibilidad de expresión, que durante muchos años fue negada a las mujeres a quienes en el ámbito de las letras les cabía, por lo general, el área de la lírica, es otros de los puntos que deben ser expuestos en la clase, pues con ello se establecen conexiones entre el escritor y el contexto social que determina o explica el tipo de obra de un determinado autor. La manera de sublimación de la incomodidad de estas mujeres se da por medio de la Literatura como elemento de denuncia de ciertas acciones y realidades sociales. Las obras de las autoras latinoamericanas comparten en general el silenciamiento de sus voces en el área de las letras, sin embargo, cada uno de los países del continente se configura como un espacio social de características determinadas en los que, por ejemplo, existieron poetas que consiguieron escribir teoría literaria y lírica, exponiéndose de manera mucho más evidente que en otros como sucedió, por ejemplo, con la contemporánea de Helena Kolody en Uruguay, cuya teoría será usada en este artículo: Idea Vilariño ${ }^{2}$.

Así, por ejemplo, tenemos al mencionar otra poeta del sur del continente no sólo

\footnotetext{
${ }^{2}$ La poeta Idea Vilariño (1920-2009) perteneció a la llamada Generación del 45 o Generación crítica de los literatos de su país, de los que participaron figuras como Ángel Rama, Ida Vitale, Mario Benedetti, entre otros. Fue profesora, traductora, poeta y crítica literaria. En el área de la lírica se destacan trabajos para el estudio y conocimiento del poema como La masa sonora del poema (2016) y Grupos simétricos en Poesía (1958).
} 
la oportunidad de comparación social de ambos países, que comparten varios aspectos históricos en común, sino que en la clase de Literatura se explican varias características de la obra de las autoras en cuestión mediante la observación de los contextos sociales en los que se desarrollaron y, además, al entendimiento de la figura de la mujer en el ámbito de las letras en América. Con respecto a la Literatura escrita por mujeres podríamos considerar que, las obras pertenecientes a mediados del siglo pasado, se apoyan en la necesidad de exponer aquello que no era posible por determinaciones del canon masculino. El porqué de este hecho se puede entender en las palabras de Rachel DuPlessis (1999), quien comenta que

[...] ¿Escribir lo no escrito, pintar no lo plasmado? es necesario hacer una poesía crítica, una lírica analítica, no una poesía que 'decora la cultura dominante' [...] sino una que cuestione los discursos. Esta situación hace de la representación un sitio de batalla. (DUPLESSIS, 1999, p. 249).

De acuerdo a lo expresado por la estudiosa, podemos comprender que es la obra lírica el espacio que escritoras como Helena Kololy utilizaron para levantar su voz comprometida y de denuncia. El poema, por lo tanto, se convierte en un objeto con la función de comunicación y, así, la obra poética que llega a la clase de Literatura pasa a ser, desde esta primera consideración introducida, un texto que dialoga con la realidad social y a la cual el lector puede comparar y sobre ella reflexionar a partir del mensaje que el poema lleva. En concordancia con lo defendido por el teórico Hans Robert Jauss (1989, p. 253) el poema, a partir de sus funciones representativas, también puede desarrollar esta función de comunicación. De acuerdo a lo expuesto por Jauss (1989, p. 253),

[...] este hecho poético, que capta la atención del lector por sus interferencias, sus elementos sobredeterminados, y lo somete a una descodificación controlada, tiene que ser portador de una significación, de un 'mensaje'. Si el poema debe imponerse a la atención no sólo por su forma sino también por su contenido, es necesario que el mensaje poético se distinga de la simple información. Podría contener, por ejemplo, una respuesta o solución de especial plausibilidad, dada de manera abierta u oculta, de modo autoritario o ambivalente, pero en todo caso deberá tener un poder de resonancia suficiente para sobrepasar el estímulo ocasional.

Por lo tanto, es posible considerar al poema, en este caso de temática de crítica social que será analizado a continuación, no sólo como un objeto que cumple una función informativa de acontecimientos, sino que incentiva a la reflexión y estimulación de la consciencia crítica en sus lectores frente a los problemas sociales, estableciendo una real comunicación entre poeta, obra y lector. Las obras que el docente presenta en la sala de clase pueden causar impacto por el nivel de identificación que se establezca con el alumnado frente a las temáticas explotadas. Estas identificaciones se generan en el acto de la lectura por la relación que el lector establece con el texto. De esta manera, el sentido de comunicación que explota la obra literaria en el lector se da, de acuerdo a las explanaciones de Wolfgang Iser (1989, p. 159), porque 
[...] al leer reaccionamos frente a lo que nosotros mismo producimos y es ese modo de reacción lo que hace que podamos vivir el texto como un acontecimiento real. No lo concebimos como un objeto dado, no lo comprendemos como una estructura determinada por predicados. Se hace presente nuestro espíritu por nuestras reacciones frente a él. El sentido del texto tiene el carácter de suceso, y, por lo tanto de un correlato de nuestra consciencia. Por ello captamos su sentido como realidad.

Esa relación que se establece entre el mensaje y el lector en el poema es un punto a destacar al momento de proponer determinadas obras líricas en la clase de Literatura. La idea que aquí planteamos no es en ningún momento la de condicionar la mirada del alumno a determinadas temáticas, sino, por el contrario, entender al poema como un texto en el que la conjunción entre lengua, mensaje y forma se da de modo consciente y que promueve la reflexión sobre determinados asuntos. Así, el poema que se expone en la clase de Literatura puede motivar en el alumnado la visión de la Literatura como una obra artística en la que el escritor plasma su compromiso social y de manera creativa expresa su enfado o encantamiento con determinadas situaciones que tienen relación directa con la sociedad circundante.

Para entender este punto y, además, ver las posibilidades analíticas del poema como objeto sonoro proponemos la obra que lleva por título "Canção de ninar (para uma criança de favela)", que pertenece al poemario Vida Breve, publicado originalmente en el año de 1964. La elección de ésta, como ya fue comentado anteriormente, se basa en dar destaque a temáticas dentro de la poética kolodyana que muestran la producción de Literatura escrita por mujeres de manera comprometida socialmente. El abordaje de este tipo de poemas, además, incentiva al alumnado a la reflexión sobre determinadas circunstancias sociales que, en Brasil específicamente, tienen una connotación negativa y se muestran como uno de los problemas sociales del país. Otro punto en que la lírica trabajada en el aula contribuye a la formación integral del sujeto es aquél del conocimiento concreto de la utilización del sistema lingǘstico crítico pero desde la perspectiva artística. La lectura de poemas en la clase pasa a ser un espacio en el que la construcción de lectores reflexivos se realiza de dos maneras: el conocimiento y uso formal de la lengua y el arte como transmisor de mensajes. A continuación el poema seleccionado para este trabajo:

\author{
Canção de ninar \\ (para uma criança da favela) \\ Criança, és fio d'agua \\ triste desde a fonte, \\ humilde plantinha \\ nascida em monturo: \\ quanta ausência mora \\ nesse olhar escuro! \\ Recosta a cabeça \\ na minha cantiga. \\ Deixa que te envolva,
}


que te beije e embale. (KOLODY, 2011, p. 136).

La lectura del poema debe realizarse de manera calma, respetando el tipo de obra propuesto. Eso aparece como un detalle menor en algunos casos, pero la declamación es un elemento sumamente importante en este tipo de texto literario. La misma puede ayudarnos en la experiencia del mensaje que el poeta pretende compartir. Un error bastante común es el de la lectura del texto lírico hecha de manera prosaica, hecho que desvirtúa este tipo de arte cuya lectura exige otros cuidados diferentes a los de la prosa. La entonación, las pausas, la velocidad, entre otros aspectos son elementos que pueden explotar mucho más el carácter del poema y descubrirnos, cuando la obra lo tiene, aspectos referentes a su construcción.

Una vez terminada la lectura del poema se procede a su análisis, atacando algunos de los "flancos" que presenta. Como primer abordaje analítico del poema, aunque no necesariamente debe comenzarse por éste, es la demostración estructural de la composición. La función estructural descubrirá al lector la ingeniería lingüística que sostiene el objeto artístico. Así, encontramos que el poema elegido para esta nuestra práctica se estructura con diez versos, divididos en dos estrofas: la primera de seis versos y la segunda de cuatro. La estructura métrica de la obra es la de una cantiga, contando en sus versos con cinco sílabas poéticas cada uno, a excepción del último verso que, siguiendo la acentuación natural presentada, está compuesto de seis sílabas.

Vemos así que desde la estructura propuesta la escritora intenta llevar al lector al mundo musical de las canciones de cuna, que ya se anuncia en el título. La estructura, además, nos invita al conocimiento del poeta como constructor de la obra elaborada cuidadosamente, que lejos de colocar versos sin conexión se propone desde su origen formal establecer lazos entre la construcción y el tema.

Este tipo de análisis estructural simple, en un principio, no nos aportaría grandes descubrimientos, sin embargo, la escansión es el camino que nos dirige a la conjunción estructura/texto. Es claro que no siempre la estructura responderá a la temática propuesta, no obstante el poema como hecho artístico, cuando bien planeado, suele ofrecer grandes revelaciones de la obra como una totalidad: forma, sonoridad y mensaje.

Como paso siguiente al ejercicio de la escansión podemos encontrar las estructuras rítmicas que sostienen al poema. Para ello utilizamos las propuestas metodológicas de la poeta y teórica Idea Vilariño (2016), destacando las vocales en las que se acentúa el poema de modo natural y elaboramos un esquema que demuestra las simetrías en la construcción lírica:

Criança, és fio d’agua

triste desde a fonte,

humilde plantinha

nascida em monturo:

quanta ausência mora

nesse olhar escuro!

Recosta a cabeça

na minha cantiga.

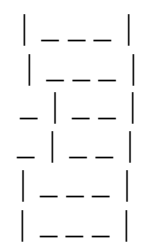

$-|--|$ 
Deixa que te envolva, que te beije e embale.<smiles>C1=[IH]2[IH]I=C12</smiles>

A partir de este esquema podemos comenzar a entender los aspectos estructurales que demuestran la musicalidad de la obra, antes de pasar al análisis temático del poema. Es posible constatar la escasa presencia de rimas en la composición, no obstante la estructura rítmica presenta construcciones que ayudan a la musicalidad del poema que, conforme será expuesto a continuación, se fundamenta en un ritmo ternario semejante al balanceo de una canción de cuna al ritmo de un vals. Antes de pasar al análisis estructural que nos demostrará el ritmo comentado, el docente podría proponer la audición en la clase de una pequeña pieza de vals para ilustrar de manera sonora la candencia ternaria. Como se está trabajando con aspectos sonoros del poema los ejemplos musicales que se deseen exponer no pueden quedar en el ámbito de lo abstracto/mental y sí, dentro de las posibilidades de cada docente, utilizar los recursos que las artes en cuestión puedan ofrecer, en este caso la apreciación musical de una obra ternaria.

Una vez explicado y/o apreciado el breve ejemplo musical se pasa al análisis del poema desde otra óptica. Para descubrir la estructura ternaria del poema de Helena Kolody procedemos a la elaboración de un cuadro compuesto de tres columnas que deben entenderse como los tres tiempos del compás del vals, T1-T2-T3, siendo el primer tiempo de acento fuerte y los otros débiles (| _ _). En cada una de las columnas serán ubicadas las sílabas del poema, a modo de una "partitura rítmica" adaptada para fines literarios. El poema en cuestión comienza en el primer tiempo del compás, fuerte, y cuya sílaba lleva el primer acento natural del verso. Las demás sílabas son colocadas en las columnas pero con diferente disposición que la encontrada en la escansión y, además, se deben considerar todas las sílabas de las palabras. Este último aspecto difiere de la convención de escansión en lengua portuguesa que se asemeja a la francesa, sin embargo tiene mucho más sentido, pues la lengua portuguesa brasileña pronuncia la sílaba final de las palabras, por lo tanto, para el análisis lírico propuesto tiene más sentido considerar ésta última sílaba, que efectivamente "suena", a favor de la naturalidad de la lengua.

Dentro de la estructura destacada corresponde a las sílabas que llevan un acento marcado en el poema el primer tiempo del compás y, por ende, en la lectura son estas sílabas las que ganan destaque y en las que se apoya el primer tiempo del vals.

\begin{tabular}{|c|c|c|}
\hline T1 & T2 & T3 \\
\hline Crian & ça, és & fio \\
\hline$d^{\prime} a$ & gua & \\
\hline Tris & te & desde a \\
\hline Fon & te, & hu \\
\hline Mil & de & plan \\
\hline$\overline{\mathrm{Ti}}$ & nha & nas \\
\hline$\overline{\mathbf{C i}}$ & $\mathrm{da} \mathrm{em}$ & mon \\
\hline $\mathrm{Tu}$ & ro: & \\
\hline Quan & ta $\mathrm{au}$ & sência \\
\hline
\end{tabular}




\begin{tabular}{|l|l|l|}
\hline Mo & ra & \\
\hline $\mathbf{N e}$ & sse o & lhar es \\
\hline $\mathbf{C u}$ & ro! & \\
\hline
\end{tabular}

Las sílabas a las que corresponde el primer tiempo del ritmo ternario dirigen la declamación del poema, que debe destacar la sonoridad de estas sílabas y no acentuar las demás. La ubicación de las otras partes de los versos se agrupa naturalmente en los dos tiempos débiles del compás presentado en el poema. Existen, conforme puede ser apreciado en el cuadro, espacios "libres" de sílabas que corresponden a silencios. Estos silencios están colocados específicamente en las partes en las que el poema exige una pausa, como en los versos 1, "Criança és fio d'agua", el verso 4, "nascida em monturo:", en el que el uso de los dos puntos sugiere una explicación o complemento de las informaciones que se expresan en el verso siguiente. El otro silencio aparece de manera significativa en el verso 5, "quanta ausência mora", para dar lugar al próximo verso que indica un lugar o espacio: "nesse olhar escuro".

Por lo tanto, de lo realizado antes podemos inferir que el aspecto musical en el poema sobrepasa el recurso de la rima o el uso de asonancias, pues es en la estructura del poema que el ritmo de canción de cuna está expresado. Este tipo de ejercicios devela, como fue comentado antes, posibilidades interesantes que, llevadas a la clase de Literatura, demuestran la conjunción de Literatura y música al momento de buscar la musicalidad de un poema.

En lo que se refiere al ritmo, destacamos lo que el estudioso Otto Károlyi (2012, p. 42) expresa, en la obra Introducción a la música:

La simple observación de la naturaleza nos ofrece ya el primer testimonio de la presencia del ritmo en el universo [...] este ritmo puede observarse hasta en la conversación cotidiana, pero es en la poesía, en la que las palabras y las sílabas están más o menos agrupadas con riguroso orden, donde somos especialmente conscientes de la existencia de ritmo.

En ese sentido, Étienne Souriau (1986, p. 193) comenta que, así como en el arte musical se establecen ciertos elementos propios de este arte como el ritmo, los matices, la melodía, la harmonía y la instrumentación, ellos aparecen también, de manera más rudimentaria, en la poesía, por medio del uso del lenguaje y sus especificidades artísticas, pero que son comunes en ambas áreas.

Esta evidencia del carácter musical de la obra de la escritora, tal vez, se explica comentando que en su formación académica tuvo contacto con el arte musical ${ }^{3}$, hecho que efectivamente influyó en sus momentos de creación. Las estructuras construidas en sus poemas denotan una inclinación a componer obras que exigen la declamación y/o el canto. Este hecho podemos corroborarlo con numerosos ejemplos, desde los más obvios como composiciones de canciones y cantigas, que revelan, mediante la forma, lo que el lector espera al leer. Pero, además, junto con estas formas poéticas es posible

\footnotetext{
${ }^{3}$ Conforme se expone en la sección "vida e obra" de su obra completa, utilizada para este trabajo, la poeta a partir del año de 1924 pasa a residir en la ciudad de Mafra, en el Estado de Santa Catarina, es allí donde comienza la escritura de sus primeros versos así como el estudio de piano y de pintura.
} 
encontrar obras cuya musicalidad se encuentra sosteniendo el cuerpo del poema en los que no se presenta necesariamente la mención a alguna forma específica del universo musical.

El próximo paso en la experiencia de análisis del poema será adentrarnos a la explicación de la temática, las imágenes y el mensaje expuestos en el cuerpo del texto. Para ello, el docente debería apreciar cada aspecto del poema con cuestionamientos a los alumnos sobre las sensaciones causadas por el uso del lenguaje poético. Así, el docente, como mediador entre la obra y el alumnado, utiliza las lecturas de éstos para el análisis de la obra lírica.

El título, primera línea a ser leída con detenimiento, contribuye, como puede ser observado en este poema, con numerosas claves para la interpretación de la obra. Desde el título, "Canção de ninar" (canción de cuna), y su subtítulo, (para uma criança da favela) (para un niño de la favela), la obra poética dialoga con el horizonte de expectativas del lector. Al principio de nuestra lectura, que comienza con el título, nos deparamos con el tipo de composición que será expuesto, una canción de cuna, que, como es de suponer, tiene dirigida su atención a la niñez. Aquí tenemos otros de los primeros puntos a favor: el juego de presentación del tema con un quiebre del horizonte de expectativas del lector/alumnado. El título ha creado en el lector el universo que se espera que sea abordado en el poema, relacionado con los aspectos que el conocimiento de mundo del lector coloca en juego al momento de pensar en los niños y canciones de cuna. Ese horizonte de expectativas es quebrado tan pronto pasamos a leer el subtítulo, en el que se nos expone el destinatario de la canción: para el niño de la favela.

Es en esta palabra, favela, en la que podemos apoyarnos para otra posibilidad de diálogo con otras ramas del saber que el docente puede aprovechar en las clases de Literatura. El término favela, corriente en el universo lingüístico brasileño, aporta miradas socio-históricas para la construcción del poema.

El término "favela" deriva de la especie vegetal llamada faveleira que es, de acuerdo con la Guia de plantas visitadas por abelhas na caatinga (2012, p. 37),

[...] uma árvore de porte pequeno, muito conhecida por possuir tricomas urticantes distribuídos por toda a planta. Essa espécie produz látex o qual é muito utilizado para fins medicinais. A faveleira destaca-se por sua grande capacidade de tolerância à seca. Suas raízes são tuberosas e armazenam nutrientes, utilizados durante a estação seca, período em que ocorre a floração e a frutificação dessa espécie.

Esta especie es característica de la región de la caatinga, en la estación seca, en el nordeste brasileño. Vemos así, que este término utilizado para determinar a comunidades o grupos sociales que carga un carácter peyorativo en algunos casos tiene su origen en una especia arbórea. Por supuesto, el término llegó a ocupar su acepción actual por acontecimientos que la lengua como elementos vivo de las sociedades sufrió e hechos históricos y de uso. Al respecto el estudioso Robert M. Levine en la obra $O$ Sertão Prometido: O Massacre de Canudos no Nordeste Brasileiro, 1893 (1995, p. 215) comenta que: 
Ao menos um dos cronistas diz que as cabanas de taipa cobertas de palha e espalhadas pelas encostas do morro da Favella é que serviram de inspiração para que os casebres construídos pelos migrantes nordestinos que invadiram o Rio de Janeiro e outras cidades do Sul do país, após a virada do século, fossem chamados de favelas. Na verdade, quando o governo atrasou o pagamento das pensões dos soldados que haviam retornado de Canudos, eles acamparam do lado de fora do Ministério da Guerra, para aguardar até que seus pedidos fossem atendidos, e batizaram sua 'cidade' de casebres com o nome de favela. A partir dessa data todas as cidades de casebres passaram a ser chamadas de favelas.

Por lo tanto, observamos que el término utilizado por la escritora permite el uso de otras áreas para explicar y debatir cuestiones de índole social y las transformaciones por las que un término usado comúnmente llegue a ser extremamente significativo. Al volver a la composición poética deducimos que, por el subtítulo, no es cualquier niño a quien la voz del yo lírico dirige su atención, sino uno específico. A partir de la lectura de ambos, título y subtítulo, componemos la totalidad del mensaje que la autora desea transmitir en esta instancia del poema: estamos frente a una canción de cuna para un niño en situación de riesgo social.

La primera estrofa es una descripción que el yo lírico realiza de su personaje destinatario: la "criança". Nuevamente tenemos en la composición la quiebra del horizonte de expectativas que la voz del yo lírico va realizando durante la caracterización del niño. El verso primero comienza con la descripción del niño como un "fio d'agua". Esta adjetivación nos remete a la transparencia y pureza con la que se asocia normalmente a la niñez. Sin embargo, el yo lírico expone en el segundo verso las particularidades de este "fio": "triste desde a fonte". La tristeza a la que alude la voz del yo lírico se expone como una consecuencia del ambiente de donde proviene ese hilo de agua, remetiendo al lector a pensar en una tristeza que viene desde sus orígenes. La segunda imagen con la que el yo lírico caracteriza al niño es la de una "humilde plantinha". Nuevamente se da el juego de quiebre del horizonte de expectativas del lector, que nos expone una planta, cuya adjetivación, humilde, y el uso del sufijo, inha, puede referirse al tamaño de la planta, y por ende nos expone a la idea de fragilidad y falta de resistencia. Por medio de esta metáfora se expresa, también, las condiciones financieras con las que son retratados los niños de las favelas. Para esta planta humilde, el yo lírico utiliza un vocablo que remete a los orígenes del ser: "nascida". El lugar en el que nació la planta es "monturo". La estrofa termina con una exclamación del yo lírico sobre el niño, destacando la palabra "ausência" que habita en su mirada. La mirada de este niño tiene algunas posibles lecturas. La primera, tenemos en ese verso la exposición de una mirada oscura, "olhar escuro!", que, en sentido figurado, puede remeter a una imagen sombría contrastando con la otorgada a la niñez a la que se le atribuye color y vida. La segunda, nos ofrece la posibilidad de entender esa mirada en sentido literal. Estamos frente a un niño de ojos oscuros, por ende, de piel oscura, que es el

\footnotetext{
${ }^{4}$ De acuerdo con el diccionario de la lengua portuguesa existe tres acepciones para la palabra: la primera, es un montón de basura o estiércol; la segunda, un basurero; y la tercera, en sentido figurado, acervo de cosas inútiles o repugnantes. Ésta información puede ser corroborada en la siguiente página: https://www.infopedia.pt/dicionarios/lingua-portuguesa/monturo, accedido el 16 de jul de 2019.
} 
contingente humano que habita, mayoritariamente, en las favelas de Brasil. Estamos frente a un niño de color y no de un inmigrante blanco. Y la tercera, es la ausencia de la familia o sociedad frente a estos niños en situación de riesgo.

En la segunda estrofa el yo lírico establece un diálogo directamente con el personaje al cual va dirigida la obra. La elección por esta forma de lenguaje, diálogo, es un recurso común en las canciones de cuna, en las que se canta directamente al niño. En el poema el yo lírico explora la imagen maternal y de cercanía entre él y el niño mediante la canción. En este sentido, consideramos que el recurso del diálogo, además de ser propio para la forma que la escritora explota, canción de cuna, es de importancia para acercar al lector la idea de conexión con el sujeto de la favela y apelar a la concientización. Otras formas diferentes al diálogo establecido no hubieran tenido el mismo impacto, puesto que éste evoca directamente la imagen de una madre con su niño en brazos. La utilización de este recurso contribuye de manera concreta a aumentar el tenor crítico del mensaje que el poema propone, pues sugiere al lector que ocupe la posición de quien dialoga con el niño al momento de la lectura.

En esta parte del poema, el yo lírico invita al niño a descansar en su canción: "Recosta a cabeça/na minha cantiga". Este acto concreto puede ser leído como una invitación a demostrar la empatía del yo lírico para con los sujetos en situación de precariedad. Los versos siguientes describen la escena final que se espera en una canción de cuna. En esta parte, el yo lírico expresa: "Deixa que te envolva,/que te beije e embale". El efecto generado por esa invitación del yo lírico en el lector genera la empatía de quien se coloca, al momento de la lectura, en el lugar de quien "envolve", "beija" y "embala" al niño. Podemos decir que la postura que asume la voz enunciadora es la de una madre que ocupa el lugar de las personas a quienes correspondería estar cuidando en este acto del niño y que, por lo comentado en el poema, "quanta ausencia", no lo hacen.

La escritora aquí nos expone desde su propio espacio, distanciado de los grandes centros culturales reconocidos de la época su trabajo lírico, cuya esencia está amalgamada a la situacionalidad universal con la cual dialoga para expresar su visión de mundo. En ese sentido, el teórico brasileño Antonio Candido (2000, p. 55) comenta que

\footnotetext{
[...] a criação literária corresponde a certas necessidades de representação do mundo, às vezes como preâmbulo a uma práxis socialmente condicionada. Mas isto só se torna possível graças a uma redução ao gratuito, ao teoricamente incondicionado, que dá ingresso ao mundo da ilusão e se transforma dialeticamente em algo empenhado, na medida em que suscita uma visão do mundo.
}

Y así vemos como la poeta, al valerse de un "lugar común", como lo son las canciones de cuna en casi todas las culturas, rompe el horizonte de expectativas del lector y reelabora frente a él un concepto originalmente dirigido a la calma, a la tranquilidad, al cuidado y a la protección. Eso, al final, confronta el lector, con la dura realidad de las diferencias sociales existentes entre los distintos estratos sociales que componen las sociedades latinoamericanas. 


\section{CONSIDERAÇÕES FINAIS}

Como fue expuesto en este artículo, es posible leer el poema desde diferentes perspectivas, pues la obra lírica permite su análisis en el sentido de la forma, del sonido y del mensaje. En la clase de Literatura podemos exponer estos puntos para el alumnado y mostrar las particularidades que el poema permite. Éste, como objeto sonoro por naturaleza, puede ser analizado estructuralmente para entender la musicalidad que lo compone. La característica sonora, lejos de situarse en el plano de la sensación o suposición, es un hecho constatable y concreto que, considerando la experiencia acústica al momento de la declamación, devela la tarea de construcción de la obra lírica. Es posible que en muchos casos las composiciones líricas que demuestran una cierta musicalidad no hayan sido concebidas de manera consciente por su artífices, sin embargo, a pesar de la casualidad aparente no dejan de mostrar el dominio auditivo del poeta en el arte de la palabra. Por otro lado, la obra lírica fundamentada en la condensación de sentidos y mensajes permite la exploración de sus temas en convergencia con otras áreas que, en definitiva, contribuyen al conocimiento de mundo del lector y ayudan al estudio del poema como objeto artístico siempre en diálogo con su contexto de producción y de recepción.

Desde estás concepciones analíticas, de forma, sonido y sentido del poema, entendemos que la clase de Literatura se muestra como el espacio ideal para generar reflexiones con los alumnos que partan de las propias obras literarias y puedan expandir los conocimientos de este arte. Los docentes y discentes tienen, así, la oportunidad de trabajar con el arte de la palabra entendiendo las múltiples posibilidades de la lengua como constructo cultural. El poema, por lo tanto, además de explotar los signos lingǘsticos puede tener una función comunicativa y un mensaje para el público lector. Este hecho se torna todavía más importante cuando descubrimos en la clase de Literatura que la obra lírica puede ser usada para, además de la exploración de la subjetividad del individuo, exponer pensamientos críticos que incentiven a una catarsis, que se da llevando al lector a la reflexión por medio del arte.

Otro de los puntos que intentamos destacar con este texto es la importancia de dar visibilidad a obras de Literatura escrita por mujeres en el continente latinoamericano que por cuestiones históricas, políticas y culturales aún hoy se encuentran en número menor que aquellas obras escritas y ubicadas en el canon literario que históricamente tuvo carácter masculino. El espacio de mujeres escritoras en el canon literario tanto en el continente americano como, y específicamente, en Brasil demanda estudios y divulgación que ayude a destacar los aspectos relevantes de sus obras, demostrando particularidades diferentes de las esperadas antiguamente como expresión de lo femenino. Así, este trabajo buscó realizar la exposición de la temática de la crítica social en la obra de una autora importante de uno de los Estado del sur de Brasil: el Paraná, ya que ella demuestra en sus obras el comprometimiento social y su voz reflexiva antes las injusticias.

Por lo tanto y para concluir, las consideraciones expuestas en este artículo que transitaron por el análisis estructural, sonoro y de sentido del poema buscaron 
demostrar que la obra lírica en la clase de Literatura necesita, por un lado, el cuidado en la selección y abordaje del contenido y, por otro, las ricas posibilidades que este objeto lírico ofrece para trabajar en la sala. El abordaje del poema, siempre y cuando éste lo permita, ofrece el diálogo con otras áreas gracias a su carácter de condensación en las informaciones expuestas en el mismo, hecho que contribuye de manera concreta en la construcción de saberes entre docente y alumnado. Así, observamos que la lírica demanda un trabajo riguroso que puede ser aprovechado de modo interdisciplinar y que en la actualidad, aunque no goce de tanto prestigio como otros géneros como la novela, por ejemplo, es un género que cuando explotado de modo profundo depara a los estudiosos y amantes de las letras con grandes posibilidades de reflexión.

\section{REFERÊNCIAS}

CANDIDO, Antonio. Literatura e Sociedade. 8. Ed. São Paulo: T. A. Queiroz, 2000.

GUERRA, Lucía. Mujer y escritura: fundamentos teóricos de la crítica feminista. Chile: Editorial Cuarto Propio, 2008.

ISER, Wolfgang. El proceso de Lectura. In: WARNING, Rainer. (Ed.). Estética de la recepción. Madrid: Visor, 1989, p. 149-164.

JAUSS, Hans Robert. La douceur du foyer-La lírica en 1857 como ejemplo de transmisión de normas sociales. In: WARNING, R. (Ed.). Estética de la recepción. Madrid: Visor, 1989, p. 251-275.

KOLODY, Helena. Infinita Sinfonia. WOELLNER, Adélia Maria (Org.). Curitiba: Edição do autor, 2011.

LEVINE, Robert M. O Sertão Prometido: O Massacre de Canudos no Nordeste Brasileiro, 1893. São Paulo: Editora da Universidade de São Paulo, 1995.

MAIA-SILVA, Camila [et al.]. Guia de plantas: visitadas por abelhas na caatinga. Fortaleza: Editora Brasil Cidadão, 2012.

KÁROLYI, Otto. Introducción a la música. Traducción de Cristina Paniagua. Madrid: Alianza Editorial, 2012.

SOURIAU, Étienne. La correspondencia de las artes. México: Fondo de cultura económica, 1986.

VILARIÑO, Idea. La masa sonora del poema. Montevideo: Biblioteca Nacional, 2016. 